\title{
Modulation of rat pancreatic acinoductal transdifferentiation and expression of PDX-1 in vitro
}

\author{
I. Rooman ${ }^{1}$, Y.Heremans ${ }^{1}$, H.Heimberg ${ }^{2}$, L. Bouwens ${ }^{1}$ \\ ${ }^{1}$ Department of Experimental Pathology, Free University of Brussels (VUB), Brussels, Belgium \\ ${ }^{2}$ Department of Metabolism and Endocrinology, Free University of Brussels (VUB), Brussels, Belgium
}

\section{Abstract}

Aims/hypothesis. In adult pancreatic regeneration models exocrine acini are found to transdifferentiate to duct-like complexes. This has also been associated with the formation of new endocrine islet cells. We aimed to establish an in vitro model in which this transdifferentiation process is characterised and can be modulated.

Methods. Purified rat pancreatic acini were cultured in suspension. Differentiation was analysed by immunocytochemistry, electron microscopy, western blotting and RT-PCR.

Results. During culture acinar cells directly transdifferentiated without dividing, the cells lost their acinar phenotype and started to express cytokeratins 20 and 7 and fetal liver kinase-1 (Flk-1) receptors for vascular endothelial growth factor. Expression of the acinar pancreatic exocrine transcription factor (PTF-1) remained and the pancreatic duodenal homeobox- containing transcription factor (PDX-1) was induced. When transdifferentiation was completed, the cells started to express protein gene product 9.5, a panneuroendocrine marker. By combining these features, the transdifferentiated cells show similar characteristics to precursor cells during active beta-cell neogenesis. We were able to modulate the differentiation state by addition of nicotinamide or sodium butyrate, agents which are known to stimulate endocrine differentiation in other models.

Conclusion/interpretation. Here, we present an in vitro system in which the cellular differentiation of putative pancreatic endocrine precursor cells and their PDX-1 expression can be modulated, thereby providing a possible model for the study of beta-cell transdifferentiation. [Diabetologia (2000) 43: 907-914]

Keywords Pancreas, differentiation, nicotinamide, sodium butyrate, PDX-1, precursor, PGP9.5.
Regeneration, or neogenesis, of beta cells in adult pancreas is an important research issue because it could find applications in the restoration of the normal beta-cell mass in diabetic patients. In vitro neogenesis might be a means of generating additional

Received: 31 January 2000 and in revised form: 23 March 2000

Corresponding author: L. Bouwens, VUB-Department of Experimental Pathology, Laarbeeklaan 103, B-1090 Brussels, Belgium

Abbreviations: BrdU, Bromodeoxyuridine; CK7, cytokeratin 7; CK20, cytokeratin 20; Flk-1, fetal liver kinase-1; PDX-1, pancreatic duodenal homeodomain containing transcription factor; PGP9.5, protein gene product 9.5; PTF-1, pancreatic exocrine transcription factor. beta cells intended for transplantation, as the number of beta cells that can be isolated from organ donors is very limited. Neogenesis can be induced in vivo in several ways [1] but the identity of the beta-cell precursors is not clear. Several lines of evidence suggest that, in addition to duct cells, exocrine acinar cells could be able to transdifferentiate into beta cells [2]. In several experimental models and pathological conditions, islet neogenesis is accompanied by the transformation of the normal exocrine tissue into ductal complexes, a process called acinoductal metaplasia. This is seen in the model of pancreatic duct ligation [3], transforming growth factor-alpha transgenic mice $[4,5]$ and interferon-gamma transgenic mice [6]. Islet neogenesis has also been observed in associ- 
ation with ductal complexes in pancreatic duct obstruction and pancreatitis in humans $[7,8]$. The formation of ductal complexes in the pancreas is at least partially caused by a transdifferentiation of acinar to duct cells [9] which illustrates the remarkable differentiation plasticity of acinar cells. In duct ligation conditions [10] and in interferon-gamma transgenic mice [6] transitional cells have been shown to coexpress amylase and insulin, suggesting a transition from acinar to beta cells. Furthermore, in vitro the acinar tumour cell line AR42J has been found to be able to differentiate into insulin-producing cells [11-13].

Conversion of acinar to duct cells in primary cultures derived from pancreas of different species has also been shown [14-16]. The phenotypic state of these cells was, however, only poorly characterised and the possibility of modulating their differentiation was not investigated. Based on these observations we sought to study the differentiation potential of rat exocrine acinar cells in vitro.

\section{Materials and methods}

Animals. Male Wistar rats of $10-12$ weeks of age (weight 250-300 g) were used for the isolations (Proefdierencentrum, Heverlee, Belgium). Experiments were approved by the ethics committee of the Free University of Brussels.

Acinar cell isolation and culture. After brief collagenase digestion of rat pancreas, the exocrine acini were separated from islets, ductal, vascular and other tissue components by centrifugal elutriation as described [17]. In brief, acini were recovered in the fraction with an average diameter less than $100 \mu \mathrm{m}$ which was washed out of the elutriator rotor running at 250 $\mathrm{rpm}$, at a counterflow rate of $240 \mathrm{ml} / \mathrm{min}$ (JB6 centrifuge, Beckman, Palo Alto, Calif., USA). Acini were cultured as aggregates in suspension within bacteriological petri dishes (Nunc, Naperville, Ill., USA). Medium consisted of RPMI1640 glutamax medium (Gibco BRL, Paisley, Scotland) supplemented with penicillin $(75 \mathrm{mg} / \mathrm{ml}$ ) (Continental Pharma, Brussels, Belgium), streptomycin (100 mg/ml) (Sigma, St Louis, Mo., USA) and $10 \%$ fetal bovine serum (Gibco BRL). The cells were kept at $37^{\circ} \mathrm{C}$ in a humid atmosphere of $5 \% \mathrm{CO}_{2}$ in air. The day of isolation was considered as day 1. Medium was replaced every day. For the study of cell replication, 5-bromo2 '-deoxyuridine (Sigma) was added at a final concentration of $10 \mu \mathrm{mol} / \mathrm{l}, 1 \mathrm{~h}$ before harvesting the cells. We did DNA assays as described [18].

Nicotinamide (niacinamide or nicotinic acid amide), 3-aminobenzamide, benzamide and sodiumbutyrate were purchased from Sigma, trichostatin A from Calbiochem (La Jolla, Calif., USA). These compounds were added to the culture in some experiments.

In some specific experiments, spheroids precultured for 4 days in suspension were cultured another day in 24-well plates (Nunc) allowing for cell adhesion to the plastic.

Immunocytochemistry. Cell pellets were fixed $1 \mathrm{~h}$ in buffered $4 \%$ formaldehyde, entrapped in a $2 \%$ agarose gel $\left(40^{\circ} \mathrm{C}\right)$ (Sigma) and processed for paraffin embedding. Paraffin sections ( $4 \mu \mathrm{m}$ thickness) were immunostained with the streptavidin- biotin method as described [19, 20]. To identify duct cells we used the mouse monoclonal antibodies anti-cytokeratin 20 (CK20; clone IT-Ks20) and anti-cytokeratin 7 (CK7; clone OVTL12/30) from Dako (Glostrup, Denmark) and affinitypurified rabbit polyclonal anti-fetal liver kinase-1 (Flk-1) (recognising the high-affinity receptor for vascular endothelial growth factor) from Santa Cruz Biotechnology (Santa Cruz, Calif., USA). We have previously shown the specificity of these antibodies [20,21]. As a marker of acinar cells we used a polyclonal rabbit antiserum against alpha-amylase (obtained from Dr. G. Klöppel, University of Kiel, Germany) [22]. To identify replicating cells in the S-phase of the cell cycle, mouse monoclonal anti-bromodeoxyuridine (BrdU) was applied (Eurodiagnostics, Apeldoorn, The Netherlands). Endocrine beta cells were identified by insulin immunostaining with a polyclonal antibody [17]. Antiserum to protein gene product 9.5 (PGP9.5) and peptide-blocked antiserum were from UltraClone (Isle of Wight, UK) [23]. To show immunoreactivity on paraffin sections, we retrieved antigen with trypsin for CK20, CK7, Flk-1 and BrdU [20, 21]. For BrdU-staining, DNA was denaturated with $2 \mathrm{~N} \mathrm{HCl}$, and the reaction was stopped with borate buffer. To measure cell proliferation, we did double immunocytochemical staining to show BrdU and CK20 as described [19-21].

To count the proportion of mononuclear and binuclear cells, we used cytospin preparations ( $900 \mathrm{rpm}$ for $7 \mathrm{~min}$ in a Shandon 3 Cytospin, Cheshire, UK) of freshly isolated cells and monolayers prepared from cells that had been precultured for 4 days in suspension and then allowed to adhere and spread on plastic for 1 day. Cytospins and monolayers were immunostained for amylase, CK20, CK7 and Flk-1 after 5 min fixation in $4 \%$ formaldehyde followed by permeabilisation in methanol $\left(10 \mathrm{~min}\right.$ at $\left.-20^{\circ} \mathrm{C}\right)$.

Electron microscopy. Cells were fixed and processed for transmission electron microscopy as described [18].

$m R N A$ and protein analysis. Total RNA (RNeasy, Qiagen, Valencia, Calif., USA) or protein was extracted from exocrine acinar cells, depleted of beta cells by the selective cytotoxic agent streptozotocin (Sigma) ( $4 \mathrm{mmol} / 1$ for $30 \mathrm{~min}$ at $37^{\circ} \mathrm{C}$ ). Cell samples were taken immediately after isolation and after 4 days of culture. As a positive control for pancreatic duodenal homeodomain containing transcription factor (PDX-1) purified beta cells were used [18].

For the semi-quantitative analysis of transcripts encoding p48 (the DNA-binding subunit of pancreatic exocrine transcription factor PTF-1) [24], PDX-1 [25] and beta-actin, $0.5 \mu \mathrm{g}$ of total RNA was reversed transcribed and amplified according to the protocol of the GeneAmp RNA-PCR kit in a GeneAmp 9600 thermocycler (Perkin Elmer Cetus, Emeryville, Calif., USA) with blanks in each assay. Primers were designed to anneal to specific sequences of $\mathrm{p}^{4}-5^{\prime}$ (codon 4-11): 5 'GCTCCTGGAGCATTTTCCCG and p48-3' (codon 48-54): 5 'CTGAGGAACTCTACCTCCGC, PDX-1-5' (codon 52-59): 5'CTCGCTGGGAACGCTGGAACA and PDX-1-3' (codon 120-127): 5 'GCTTTGGTGGATTTCATCCACGG, yielding amplified fragments of 285 and 224 base pairs, respectively. Specific primers for control amplifications were: beta-actin-5' (codon 249-255): 5 'ACTATCGGCAATGAGCGGTTC, beta-actin-3' (codon 338-344): 5 'AGAGCCACCAATCCACACAGA (288 bp fragment). The cycling profile was: $2 \mathrm{~min}$ at $95^{\circ} \mathrm{C}$ followed by $0.5 \mathrm{~min} 94^{\circ} \mathrm{C}$, $0.5 \mathrm{~min} 60^{\circ} \mathrm{C}$ and $1.5 \mathrm{~min} 72^{\circ} \mathrm{C}$ for 10 cycles and $0.5 \mathrm{~min}$ $94^{\circ} \mathrm{C}, 1 \mathrm{~min} 58^{\circ} \mathrm{C}$ and $1.5 \mathrm{~min} 72^{\circ} \mathrm{C}$ for 10 to 18 cycles. Analysis of the amplified fragments (28 cycles for p48 and PDX-1, and 21 cycles for beta-actin) was done on ethidium bromide stained agarose gels. 
Proteins were extracted in radioimmunoprecipitation (RIPA) buffer and their concentration was measured using the BCA method (Pierce, Rockford, Ill., USA). Equal amounts of protein were separated on $10 \%$ SDS-polyacrylamide gels and electroblotted to nitrocellulose membranes [26]. The blotted filters were incubated for $60 \mathrm{~min}$ at room temperature with a polyclonal PDX-1 antiserum (Ab 1859) (dilution: 1/500) that was generated against glutathion $S$-transferase (GST)-PDX-1 fusion protein containing the $63 \mathrm{C}$-terminal amino acids of rat PDX-1 [25]. Blotting efficiency was tested by total protein staining (Ponceau, Sigma). Anti-rabbit horseradish peroxidase-coupled antibody was applied (dilution: 1/1000) and the enzyme-derived chemiluminescence (ECL) kit (Amersham) was used for immunodetection.

In situ hybridisation. Preproinsulin mRNA was detected as described previously [27].

Statistics. Results are presented as means \pm SEM. Data were analysed by Student's $t$ test (Stat Works, Cricket Software, Philadelphia, Pa., USA) and statistical significance was considered to be present at a $p$ value of less than 0.05 . Each experiment was repeated independently at least three times.

\section{Results}

Transdifferentiation of acinar cells to ductal cells. Preparations of centrifugally elutriated acini from adult rats were initially composed of approximately $90 \%$ acinar cells, characterised by amylase immunostaining (light microscopy) and by the presence of zymogen granules and stacks of rough endoplasmic reticulum (electron microscopy). Centroacinar and ductular cells comprised less than $10 \%$ of the cells in these preparations and were characterised by cytokeratin 20 (CK20) immunoreactivity and lack of amylase immunoreactivity (light microscopy), absence of zymogen granules and endoplasmic reticulum stacks (electron microscopy). Less than $0.5 \%$ of all cells represent insulin-positive endocrine beta cells. Based on their ultrastructural integrity (electron microscopy) the acini showed a viability greater than $90 \%$ after isolation.

During the first 2 days in suspension culture supplemented with $10 \%$ serum, which is essential in these experiments, the acini formed cell aggregates that showed a lumpy surface due to the presence of bulging cells (phase contrast microscopy). After 3 days of culture, these aggregates became smooth spheroids. Immunocytochemical analysis (Figs. 1, 2) showed a very sharp decline in the frequency of cells with acinar characteristics between 2 and 4 days of culture. By the 5 th day, the spheroids were composed of $87 \pm 2 \%$ of amylase-negative, CK20-positive cells, i.e. cells with a ductal phenotype [20]. Electron microscopic analysis confirmed the nearly complete switch from acinar to ductal morphotype within 4 days of culture as $92 \pm 3 \%$ of the cells had ductal characteristics; $8 \pm 4 \%$ retained acinar cell characteristics $(n=4)$. The ductal morphotype included the ab- sence of zymogen granules and endoplasmic reticulum stacks, and a relative abundance of mitochondria, microvilli and intercellular junctions.

Between day 2 and day 5, we noticed, with electron microscopy, frequent apoptotic acinar cells. Analysis of total DNA content in that time period showed that between 26 and $64 \%$ of the initial amount of DNA remained in the culture. In the same time, a ninefold increase in the percentage of cells with ductal phenotype was observed (Fig. 2). Estimation of absolute numbers of ductal cells by multiplying their relative number with total DNA content indicated a fourfold increase in duct cell number within 3 days (Fig.2). Bromodeoxyuridine (BrdU) immunocytochemistry excluded the possibility of selective expansion of contaminating ductal cells as there were no BrdU/CK20-double positive cells between day 1 and 5 (not shown). These suspension cultures contained only very few BrdU-positive cells and these were vimentin-positive, probably representing contaminating fibroblasts. Contaminating fibroblasts became more numerous during the culture but the high enrichment in ductal cells was still seen after 10 days of culture, which was the end of the experiment (Fig. 2).

Counts in cytospins prepared from acinar cells on the day of isolation showed that $63 \pm 2 \%$ were binuclear. When we allowed spheroids on day 4 to attach and spread on plastic for 1 day, we could count the percentage of cells on day 5 that were binuclear. An average of $59 \pm 3 \%(n=4)$ of the cells contained two nuclei. Analysis of the cells in the monolayers showed that they express the ductal phenotype, similar to suspension-cultured cells on day 5 (not shown). Incorporation of BrdU certified that these were not mitotic cells. This is direct proof that the CK20-positive cells were derived from acinar cells.

In the absence of fetal bovine serum, the cells failed to transdifferentiate and did not survive.

The transdifferentiated cells have characteristics of pancreatic duct cells. Immunocytochemical examination showed the expression of cytokeratin-7 (CK7) and Flk-1 in the transdifferentiated cells, whereas both markers were initially absent (not shown). In the adult pancreas CK7 and Flk-1 are localised normally only in the larger pancreatic duct elements as shown previously $[20,21,28]$. During embryonic development $[2,19,28,29]$ and in acinoductal complexes induced by pancreatic duct ligation ([21], own unpublished observations), duct cells are also characterised by expression of CK7 and Flk-1.

Transdifferentiation is inhibited by nicotinamide. When nicotinamide was added to the culture medium, a strong inhibition of transdifferentiation was noticed (Fig. 3). Nicotinamide prevented the loss of amylase immunoreactivity as well as the increase in 

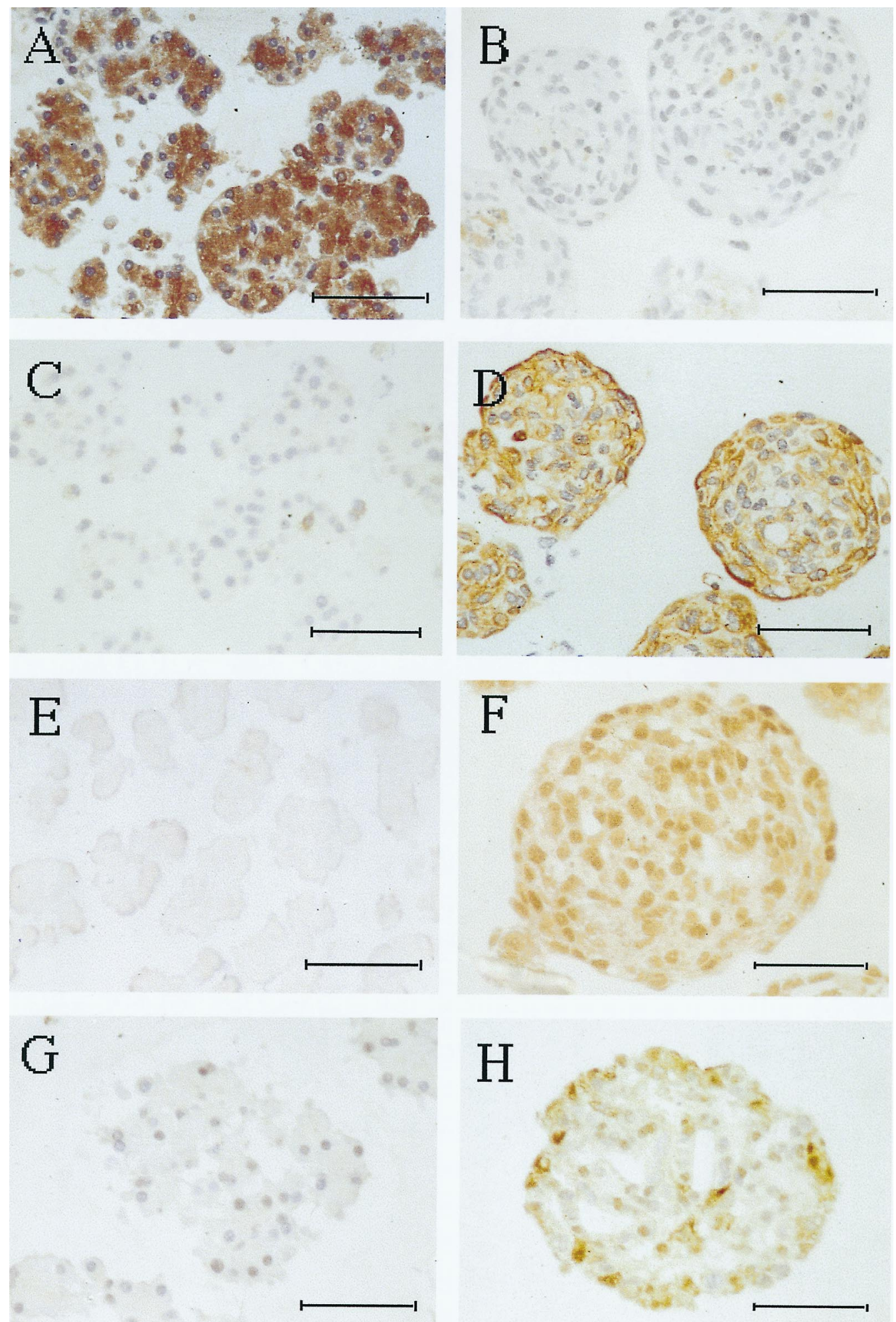

Fig.1A-H. Cells in suspension culture on day $2(\mathbf{A}, \mathbf{C}, \mathbf{E}, \mathbf{G})$, on day $5(\mathbf{B}, \mathbf{D}, \mathbf{F})$ and on day $10(\mathbf{H})$, immunostained for alpha-amylase (A and B), cytokeratin-20 (C and D), PDX-1 $(\mathbf{E}$ and $\mathbf{F})$ and PGP9.5 (G and $\mathbf{H})$. Scale bar $=40 \mu \mathrm{m}$. $\mathbf{E}$ and $\mathbf{F}$ : nuclei are not stained with haematoxylin

expression of CK20, CK7 and Flk-1. On day 5 the effect was noted with 10, 20 and $40 \mathrm{mmol} / \mathrm{l}$ (approximately $80 \%$ of the cells being amylase-positive) (Fig. 3).

Electron microscopic analysis showed a dosedependent inhibition of nicotinamide on acinar cell transdifferentiation with up to $80 \%$ acinar cells remaining on day 5 (not shown). Part of the cells that 

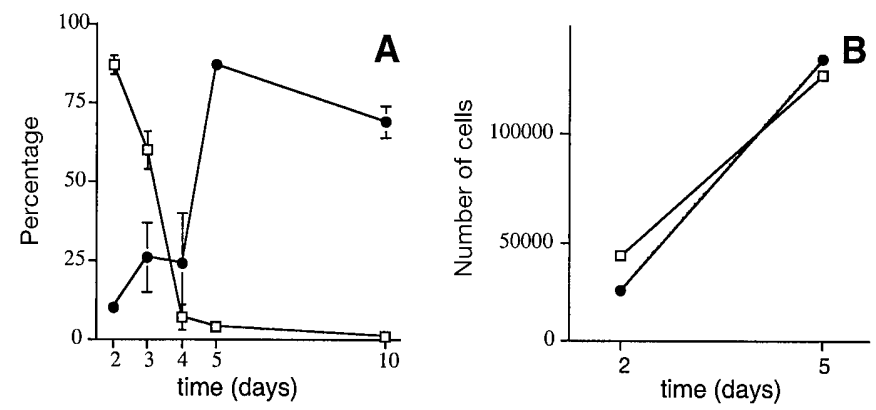

Fig. 2. A Composition of the cell cultures from day 2 to day 10 as assessed by immunocytochemistry for \% amylase $(-\square)$ and \% CK20 (-) $(n=4-6)$. B Estimation of absolute numbers of ductal cells during time by multiplying DNA content (ng/sample) with \% CK20-immunoreactive cells (-) or with \% ductal cells $(-\square-)$ counted by electron microscopy $(n=3-4)$

were devoid of zymogen granules were considered to represent degranulated acinar cells because they still contained a large amount of stacked endoplasmic reticulum (not shown). Total DNA measurements showed that there was no increase in cell survival with nicotinamide concentrations of 10 and $20 \mathrm{mmol} / \mathrm{l}$ but with $40 \mathrm{mmol} / \mathrm{l}$ we observed a better survival, $68 \pm 7 \%$ of initial DNA remained at day 5 compared with $39 \pm 4 \%$ in controls $(n=4)$. A secondary effect on cell survival of nicotinamide at the highest concentration cannot therefore be excluded. Nicotinamide did not induce proliferation of the cells (not shown). In cultures exposed, from day 1 to 5 , to 2-20 mmol/1 3-aminobenzamide, $10-20 \mathrm{mmol} / \mathrm{l}$ benzamide, $5 \mathrm{mmol} / \mathrm{l}$ sodium butyrate or $0.1 \mathrm{mmol} / \mathrm{l}$ trichostatin similar results were obtained as described above for nicotinamide but exposure to $0.1 \mathrm{mmol} / \mathrm{l}$ benzamide had no measurable effect.

Redifferentiation. Spheroids on the 5th day of culture, with ductal phenotype, were cultured for another 5 days in the presence of $10-40 \mathrm{mmol} / \mathrm{l}$ nicotinamide or $5 \mathrm{mmol} / \mathrm{l}$ sodium butyrate. The results showed a re-appearance of exocrine acinar characteristics in the transdifferentiated cells treated with nicotinamide: up to $42 \%$ amylase-positive, CK20-negative cells in the presence of nicotinamide compared with $1 \%$ in control conditions on day 10 (Fig. 3). The values for CK20-positive and amylase-positive cells did not always add up to $100 \%$. Electron microscopic analysis of these samples showed that they contained more acinar cells that were poorly granulated as well as non-granulated cells which were identified as acinar on the basis of abundant endoplasmic reticulum stacks (not shown). Thus, there were $57 \%, 54 \%$, and $51 \%$ cells with ductal morphology, $22 \%, 33 \%$ and $37 \%$ granulated acinar cells and $19 \%, 13 \%$, and $12 \%$ non-granulated acinar cells for 10, 20 and $40 \mathrm{mmol} / \mathrm{l}$ nicotinamide, respectively $(n=3)$. The discrepancy between the percentage of cells expressing
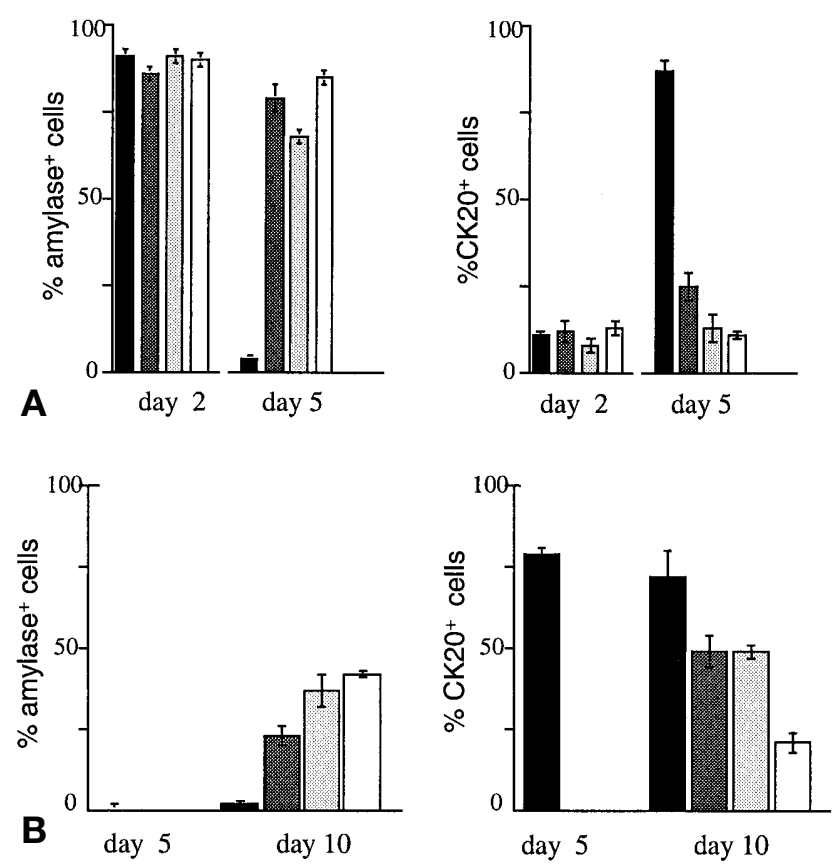

Fig. 3 A, B. Composition of the cell cultures as assessed by immunocytochemistry for amylase and CK20. A on day 2 and day 5 in the presence of $0,10,20,40 \mathrm{mmol} / 1$ nicotinamide (NA) $(n=3-4)$. B on day 5 and after exposure from day 5 to day 10 to NA $(0,10,20$ and $40 \mathrm{mmol} / \mathrm{l})(n=3-4)$. $\mathbf{\square}, 0 \mathrm{mmol} / \mathrm{l} \mathrm{NA}$; , $10 \mathrm{mmol} / \mathrm{l} \mathrm{NA} ; \square, 20 \mathrm{mmol} / \mathrm{l} \mathrm{NA} ; \square, 40 \mathrm{mmol} / \mathrm{l} \mathrm{NA}$

CK20 and the percentage ductal cells as scored by electron microscopy could be due to the ductal cells which had already lost CK20 as a first step in the redifferentiation process.

Sodium butyrate did not alter the differentiation state of the ductal spheroids.

This shows that addition of nicotinamide at a later stage of the culture induces redifferentiation in those cells which were already transdifferentiated.

Transdifferentiated cells express the pancreatic-duodenal homeobox transcription factor PDX-1 and the exocrine pancreatic transcription factor PTF-1 (p48 subunit). We examined the expression of the pancreatic homeodomain-containing transcription factor PDX-1 [30] and of the heterooligomeric transcription factor PTF-1, of which the p48 DNA-binding subunit belongs to the family of basic helix-loop-helix proteins [24] before and after transdifferentiation. Immunocytochemical analysis showed that freshly isolated cells lack PDX-1 immunoreactivity, but most transdifferentiated cells had nuclear PDX-1 immunoreactivity on day 5 of culture and thereafter (Fig.1). No reactivity was found when the antibody was preabsorbed with the corresponding antigen (not shown). Western blot of cellular extracts (Fig. 4) showed a protein band of approximately $\mathrm{M}_{\mathrm{r}} 40000$ which is concordant with the reported molecular weight of rat PDX-1 [25]. The intensity of this band 


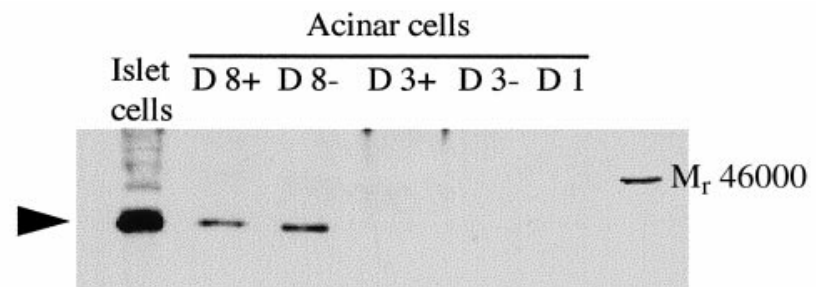

Fig. 4. Western Blot for PDX-1 detection in islet and acinar cells at day 1 (D1), day 3 (D3) and day 8 (D8) with (+) or without $(-)$ treatment of the cells with the beta-cell selective toxin streptozotocin

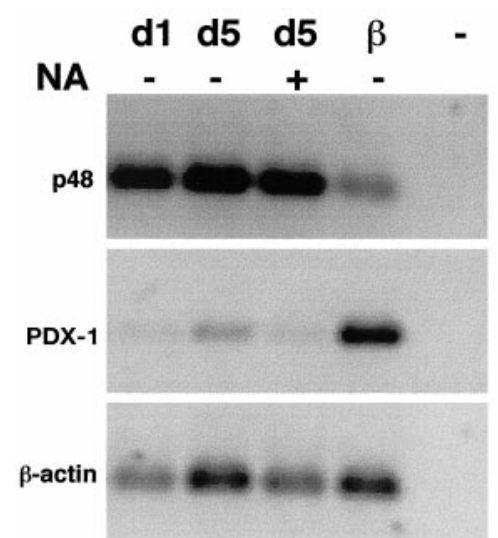

Fig. 5. Expression of p48 and PDX-1 as determined by RTPCR at day 1 (D1) and day 5 (D5) in the presence (+) or absence $(-)$ of $20 \mathrm{mmol} / \mathrm{l}$ nicotinamide (NA).Beta cells were used as control

remained unaffected in cell preparations that had been pretreated with streptozotocin to selectively destroy possibly contaminating beta cells $(<0.5 \%$ of the cells as analysed by immunocytochemistry for insulin).

Semi-quantitative RT-PCR showed that p48 remained expressed in the transdifferentiated cells whereas this transcription factor subunit was less abundant in beta cells. During transdifferentiation PDX-1 mRNA transcripts were induced (Fig.5). A very faint band in the freshly isolated acinar cell preparations was probably due to a minimal contamination by beta cells $(<0.5 \%)$. Inhibition of transdifferentiation by nicotinamide also repressed the increase of PDX-1 mRNA abundance but p48 levels did not differ (Fig. 5).

During culture, the transdifferentiated cells start to express a pan-neuroendocrine marker protein gene product 9.5 (PGP9.5). When the acinar cells were transdifferentiated and further cultured under the same conditions for another 5 days, $55 \pm 3 \%$ of the cells became immunoreactive for the pan-neuroendocrine marker, PGP9.5 [23] but no reactivity could be detected in the initial cell preparations (Fig.1) or when the antibody was preabsorbed with the corre- sponding antigen. By immunocytochemistry and hybridisation in situ, the cells remained negative for insulin protein and mRNA.

\section{Discussion}

A rapid "spontaneous" acinar to ductal cell transdifferentiation has been described in cultured exocrine pancreas from mouse [15], rat and guinea pig [14] and human [16] origin. In this study with rat acini, we confirm and extend these studies using the recently described markers of ductal differentiation CK 20 and CK 7 [20, 28] and Flk-1 receptors [21, 29]. Within 4 days of culture, the pancreatic cell aggregates which were initially highly enriched in cells with acinar phenotype (approximately 90\% amylase-positive, CK20negative) had acquired the ductal phenotype (approximately $90 \%$ amylase-negative, CK20-positive). A steep decrease in immunoreactivity for amylase was seen between day 3 and day 4 , followed by a steep rise in immunoreactivity for CK20 between day 4 and day 5. On day 4, which represents the time of phenotypic switch, "transitional" cells showed characteristics of neither acinar cells nor ductal cells. The occurrence of transitional cells with no obvious phenotypic status is a common observation in the transdifferentiation pathway of other cell types, e. g. differentiation of pigmented epithelial cells into lens cells [31]. These observations, a ninefold increase in cells with ductal characteristics with 26 to $64 \%$ preservation of initial DNA, and the absence of cell division as assessed by incorporation of BrdU, excluded the possibility of selective survival or overgrowth by a small contaminating population of centroacinar-ductular cells. We have previously shown the reliability of BrdU/CK20 double-immunostaining in detecting proliferating duct cells [21]. The present results are indicative of a process termed "direct transdifferentiation", in which cellular phenotypic conversion is independent from DNAreplication [32]. Furthermore we counted that approximately $60 \%$ of the transdifferentiated cells were binucleated, which is characteristic for acinar cells. This observation accords with the results of others [33], showing that ductal cells are mononuclear and approximately $65 \%$ of acinar cells have two nuclei.

The transdifferentiated cells expressed CK7 and the VEGF-receptor Flk-1, which are characteristics of the large intralobular, the interlobular and main ducts but are not detected in intralobular ductules and centroacinar cells in normal adult pancreas [20, $21,28]$. These markers are also known to be expressed during pancreatic morphogenesis in the fetus $[28,29]$ and in adult regeneration models induced by partial pancreatectomy or ligation of the duct where acinoductal metaplasia is induced [3,21].

Analysis by RT-PCR, western blotting and immunocytochemistry showed that the transdifferentiated 
cells have a sustained expression of the exocrine transcription factor PTF-1 [24] and in addition start to coexpress PDX-1. The latter (also termed IDX, IPF-1 or STF-1) is a homeodomain-containing transcription factor which binds and transactivates the insulin promotor [30] and is crucial for pancreatic organogenesis [34]. It is detected in all embryonic protodifferentiated epithelial cells during pancreatic development [35]. In adults, strong PDX-1 expression is found in beta cells and in a subpopulation of delta cells [35]. This transcription factor generally acts as a master regulator of beta-cell development. In our study no PDX-1 mRNA or protein was detected in normal acinar cells but it was induced after transdifferentiation. Also, in vivo, where beta-cell neogenesis can be induced by pancreatic duct ligation (own unpublished observations), partial pancreatectomy [36] or, in transgenic mice, overexpressing transforming growth factor-alpha [5] or interferon-gamma [37], the formation of new beta cells is preceded by expression of PDX-1 in the precursor acinoductal complexes. When transdifferentiation was completed and the cells were kept further in culture, $55 \%$ of the cells were found to stain positive for PGP9.5, which is an isoform of ubiquitine carboxyterminal hydrolase (UCTH-L1) and considered to be a marker for neurons and neuroendocrine cells including pancreatic islet cells [23]. It is also found in ductal cells during embryonic islet morphogenesis or after pancreatic duct ligation (own unpublished observations). The combination of the ductal phenotype together with PDX-1 and PGP9.5 expression suggests partial differentiation towards islet cells but insulin expression was lacking. The possibility should be investigated whether these cells have the potential to differentiate into insulin-expressing cells in vitro, which may depend on the presence of appropriate morphogenic factors. At present we cannot exclude, however, that the differentiation potential of the transdifferentiated cells is limited to exocrine cell commitment.

We found chemical agents that could prevent or reverse the acinoductal transdifferentiation in vitro. Nicotinamide inhibited the acinoductal conversion so that a considerable proportion of acinar cells retained their differentiated state at the 5th day of culture. When transdifferentiation was allowed to occur and nicotinamide was added thereafter, $40-50 \%$ of the cells which had switched from an acinar to a ductal phenotype were induced to regain acinar characteristics and lose ductal characteristics, which shows that the transdifferentiation is reversible. Nicotinamide, as well as 3-aminobenzamide and benzamide which we found to inhibit transdifferentiation, are potent inhibitors of ADP-ribosylation [38]. Involvement of ADP-ribosylation in differentiation processes has been described previously $[39,40]$. Sodium butyrate and trichostatin A also inhibited the transdifferentiation process. These agents are established cell-differentiating agents which inhibit histone deacetylation and hence inhibit gene repression. Notably, nicotinamide has been shown to induce the development of endocrine cells from fetal pancreas in vitro [41] and after transplantation [42] and can stimulate beta-cell regeneration in partially pancreatectomised rats, thereby preventing diabetes [43]. Sodium butyrate is also known to affect endocrine differentiation [44]. These compounds therefore already have a documented effect on cell differentiation in the pancreas. It is not clear why we found an apparent opposite effect, i.e. promotion of exocrine instead of endocrine differentiation. It is possible that for instance a combination of nicotinamide or sodium butyrate and the presence of fetal mesenchymal cells [41, 42, 44] would have a different effect than in our model.

We showed that by addition of ADP-ribosylation inhibitors or inhibitors of histone deacetylase the differentiation of normal adult pancreatic cells can be manipulated in vitro. The transdifferentiated cells express CK7, CK20, Flk-1, PDX-1 and PGP9.5, a combination of markers also found during active betacell neogenesis in cells which are believed to represent the islet precursor cells. This in vitro model could contribute to the study of beta-cell differentiation from adult pancreatic cells.

Acknowledgements. The authors are grateful to Dr. G. Klöppel (University of Kiel, Germany) for anti-amylase, to Dr. O. Madsen (Hagedorn Research Institute, Denmark) for providing anti-PDX-1, and to Dr. D. Pipeleers (Free University of Brussels, Belgium) for logistic and general support. The authors thank M. Berghmans, E. De Blay, A. Nuyts and K. Sterck for technical assistance. This work was supported by the Belgian Fund for Scientific Research (FWO G0041.96). I. Rooman and H. Heimberg are respectively a research fellow and a post-doctoral research fellow from the Fund of Scientific Research-Flanders (Belgium).

\section{References}

1. Bouwens L, Klöppel G (1996) Islet cell neogenesis in the pancreas. Virchows Arch 427: 553-560

2. Bouwens L (1998) Transdifferentiation versus stem cell hypothesis for the regeneration of islet beta-cells in the pancreas. Microsc Res Tech 43: 332-336

3. Wang RN, Klöppel G, Bouwens L (1995) Duct to islet cell differentiation and islet growth in the pancreas of duct ligated adult rats. Diabetologia 38: 1405-1411

4. Bockman DE, Merlino G (1992) Cytological changes in the pancreas of transgenic mice overexpressing transforming growth factor alpha. Gastroenterology 103: 1883-1892

5. Song SY, Gannon M, Washington MK et al. (1999) Expansion of Pdx-1-expressing pancreatic epithelium and islet neogenesis in transgenic mice overexpressing transforming growth factor alpha. Gastroenterology 117: 1416-1426

6. Gu D, Arnush M, Sarvetnick N (1997) Endocrine/Exocrine intermediate cells in streptozotocin-treated Ins-IFN-gamma transgenic mice. Pancreas 15: 246-250

7. Klöppel G, Bommer G, Commandeur G, Heitz P (1978) The endocrine pancreas in chronic pancreatitis. Virchows Arch 377: 157-174 
8. Bartow SA, Mukai K, Rosai J (1981) Pseudoneoplastic proliferation of endocrine cells in pancreatic fibrosis. Cancer 47: 2627-2633

9. Bockman DE (1995) Toward understanding pancreatic disease: from architecture to cell signaling. Pancreas 11: 324-329

10. Bertelli E, Bendayan M (1997) Intermediate endocrineacinar pancreatic cells in duct ligation conditions. Am J Physiol 273: C1641-C1649

11. Mashima H, Ohnishi H, Wakabayashi K et al. (1996) Betacellulin and actvin A coordinately convert amylase-secreting pancreatic AR42J cells into insulin-secreting cells. J Clin Invest 97: 1647-1654

12. Mashima H, Shibata H, Mine T, Kojima I (1996) Formation of insulin-producing cells from pancreatic acinar AR42J cells by Hepatocyte Growth factor. Endocrinology 137: 3969-3976

13. Zhou J, Wang X, Pineyro MA, Egan JM (1999) Glucagonlike Peptide 1 and Exendin-4 convert pancreatic AR42J cells into glucagon- and insulin-expessing cells. Diabetes 48: 2358-2366

14. Arias AE, Bendayan M (1993) Differentiation of pancreatic acinar cells into duct-like cells in vitro. Lab Invest 69: 518-530

15. De Lisle RC, Logsdon CD (1990) Pancreatic acinar cells in culture: expression of acinar and ductal antigens in a growth-related manner. Eur J Cell Biol 51: 64-75

16. Hall PA, Lemoine NR (1992) Rapid acinar to ductal transdifferentiation in cultured human exocrine pancreas. $\mathrm{J} \mathrm{Pa}$ thol 166: 97-103

17. Pipeleers DG, Pipeleers-Marichal M, Hannaert JC et al. (1991) Transplantation of purified islet cells in diabetic rats. I. Standardization of islet cell grafts. Diabetes 40: 908-919

18. Pipeleers DG, In't Veld P, Van De Winkel M, Maes E, Schuit FC, Gepts W (1985) A new in vitro model for the study of pancreatic A and B cells. Endocrinology 117: 806-816

19. Bouwens L, Wang RN, De Blay E, Pipeleers DG, Klöppel G (1994) Cytokeratins as markers of ductal cell differentiation and islet neogenesis in the neonatal rat pancreas. Diabetes 43: 1279-1283

20. Bouwens L, Braet F, Heimberg H (1995) Identification of rat pancreatic duct cells by their expression of cytokeratins 7, 19 and 20 in vivo and after isolation and culture. J Histochem Cytochem 43: 245-253

21. Rooman I, Schuit F, Bouwens L (1997) Effect of vascular endothelial growth factor on growth and differentiation of pancreatic ductal epithelium. Lab Invest 76: 225-232

22. Morohoshi T, Kanda M, Horie A et al. (1987) Immunocytochemical markers of uncommon pancreatic tumors. Acinar cell carcinoma, pancreatoblastoma, and solid cystic (papillary-cystic) tumor. Cancer 59: 739-747

23. Thompson RJ, Doran JF, Jackson P, Dhillon AP, Rode J (1983) PGP 9.5 - a new marker for vertebrate neurons and neuroendocrine cells. Brain Res 278: 224-228

24. Krapp A, Knöfler M, Frutiger S, Hughes GJ, Hagenbüchle O, Wellauer PK (1996) The p48 DNA-binding subunit of transcription factor PTF1 is a new exocrine pancreas-specific basic helix-loop-helix protein. EMBO J 15: 4317-4329

25. Serup P, Jensen J, Andersen FG et al. (1996) Induction of insulin and islet amyloid polypeptide production in pancreatic islet glucagonoma cells by insulin promoter factor 1 . Proc Natl Acad Sci USA 93: 9015-9020

26. Heimberg H, De Vos A, Moens K et al. (1996) The glucose sensor protein glucokinase is expressed in glucagon-producing alpha-cells. Proc Natl Acad Sci USA 93: 7036-7041
27. Wang RN, Bouwens L, Klöppel G (1994) Beta-cell proliferation in normal and streptozotocin-treated newborn rats: site, dynamics and capacity. Diabetologia 37: 1088-1096

28. Bouwens L (1998) Cytokeratins and cell differentiation in the pancreas. J Pathol 184: 234-239

29. Oberg C, Waltenberger J, Claesson-Welsh L, Welsh M (1994) Expression of protein tyrosine kinases in islet cells: possible role of the flk-1 receptor for beta cell maturation from duct cells. Growth Factors 10: 115-126

30. Ohlsson H, Karlsson K, Edlund T (1993) IPF1, a homeodomain-containing transactivator of the insulin gene. EMBO J 12: 4251-4259

31. Agatha K, Kobayashi H, Itoh Y, Mochii M, Sawada K, Eguchi G (1993) Genetic characterization of the multipotent dedifferentiated state of pigmented epithelial cells in vitro. Development 118: 1025-1030

32. Beresford WA (1990) Direct transdifferentiation: can cells change their phenotype without dividing? Cell Differ Dev 29: 81-93

33. Oates PS, Morgan RG (1989) Cell proliferation in the exocrine pancreas during development. J Anat 167: 235-242

34. Jonsson J, Carlsson L, Edlund T, Edlund H (1994) Insulinpromotor-factor 1 is required for pancreas development in mice. Nature 371: 606-609

35. Guz Y, Montminy MR, Stein R et al. (1995) Expression of murine Stf-1, a putative insulin gene transcription factor, in beta cells of pancreas, duodenal epithelium and pancreatic exocrine and endocrine progenitors during ontogeny. Development 121: 11-18

36. Sharma A, Zangen DH, Reitz P et al. (1999) The homeodomain protein IDX-1 increases after an early burst of proliferation during pancreatic regeneration. Diabetes 48 (3): 507-513

37. Kritzik MR, Jones E, Chen Z et al. (1999) PDX-1 and Msx2 expression in the regenerating and developing pancreas. $\mathrm{J}$ Endocrinol 163: 523-530

38. Banasik M, Ueda K (1994) Inhibitors and activators of ADP-ribosylation reactions. Mol Cell Biochem 138: 185-197

39. Althaus FR, Lawrence SD, He YZ, Sattler GL, Tsukada Y, Pitot HC (1982) Effects of altered (ADP-ribose)n metabolism on expression of fetal functions by adult hepatocytes. Nature 300: 366-370

40. Kharadia SV, Huiatt TW, Huang HY, Peterson JE, Graves DJ (1992) Effect of Arginine-Specific ADP-Ribosyltransferase Inhibitor on Differentiation of Embryonic chick Skeletal Muscle Cells in Culture. Exp Cell Res 201: 33-42

41. Otonkoski T, Beattie GM, Mally MI, Ricordi C, Hayek A (1993) Nicotinamide is a potent inducer of endocrine differentiation in cultured human fetal pancreatic cells. J Clin Invest 92: 1459-1466

42. Beattie G, Rubin J, Mally M, Otonkoski T, Hayek A (1996) Regulation of proliferation and differentiation of human fetal pancreatic islet cells by extracellular matrix, Hepatocyte Growth Factor, and cell-cell contact. Diabetes 45: 1223-1228

43. Yonemura Y, Takashima T, Miwa K, Miyazaki I, Yamamoto H, Okamoto H (1984) Amelioration of diabetes mellitus in partially depancreatized rats by poly(ADP-ribose)synthetase inhibitors. Diabetes 33: 401-404

44. Otonkoski T, Ustinov J, Rasilainen S, Kallio E, Korsgren O, Hayry P (1999) Differentiation and maturation of porcine fetal islet cells in vitro and after transplantation. Transplantation 68: 1674-1683 